\title{
MASCULINITY OF HEROINE IN XENA: WARRIOR PRINCESS (1995) AND THE HUNGER GAMES (2012)
}

\author{
Ingga Rosarini ${ }^{1}$, Pepi Siti Paturohmah ${ }^{2}$, and Hasbi Assiddiqi ${ }^{3}$ \\ SMK Mahardhika ${ }^{1}$, \\ Universitas Islam Negeri Sunan Gunung Djati Bandung ${ }^{2}$ \\ Universitas Islam Negeri Sunan Gunung Djati Bandung ${ }^{3}$
}

\begin{abstract}
This study aims at revealing the female masculinity or masculine character reflected in the character heroine of Katniss Everdeen and Xena. The characters created are also both heroes mostly born in the adventure genre. Heroine is the female protagonist character. The hero overcomes these opponents because he is strong, brave, resourceful, rational, and determined to succeed, he may receive assistance from wise and benefit being who recognize him for what he is. The words masculine can refer to the property of being biologically male. Inferiority to high culture is derived from, and refer back to, the sexist constructions of femininity and masculinity in the wider society. The researcher looks for data relating to the question of the problem, how are the masculinity aspect of heroine described in Xena: Warrior Princess and The Hunger Games Movie. The researcher used comparative method to find differences and similarities of both characters to be used as the objects of research with the topic woman characters. From the analysis, it was found that Katniss and Xena had masculinity of heroine. This also shows a striking difference in both characters.
\end{abstract}

Keywords: heroine, masculinity, comparative, film, sexist

\section{INTRODUCTION}

Film becomes one of the important alternative parts in literature because it contains direct ideas. In other respects, film as an art where film always shows social things. Dividing the film into various elements for analysis is an important process. This applies when films from one element to another are interconnected. In analyzing films, we can use three approaches for textual analysis, genre analysis, and production analysis. Perceptive film analysis relies on the principles used in literary analysis. Therefore, before we move on to the unique elements of the film, we need to look at the elements that the film shares with a good story (Boggs \& Petrie, 2008, p. 41). Besides that, film is modern art which always spreads to all parts of other societies.

Film has a different type of genre. Genre is also literature that has a certain form, category, or classification. One form of genre classification is adventure genre. The characters created are also both heroes mostly born in the adventure genre. The name of the female action hero is heroine. According to Sarick (2009, p. 15), the adventure genre is experiencing an uplifting experience, because readers and viewers shout for tense actions packed with mission stories and treasure hunts, full of danger and suspense, with interesting details, full of obstacles and great character that we like even for us to hate.

The addition of female characters and making women the main characters is one of the reasons why women are the topics to be discussed. The addition of female 
characters and important roles that were previously dominated by men later in the Star Wars VII: The Force Awakens (2015) are played by women. In those film is also a very sharp representation of women, where women play an important role in resolving cases and have the same position as men.

Inferiority to high culture is derived from, and refer back to, the sexist constructions of femininity and masculinity in the wider society. The American action cinema constructs gender roles, particularly the portrayal of the female characters as action heroines. Gender is a form of culture or social construction, not all women are feminine and not all men are masculine, it depends on the social and cultural conditions that construct both. The formation of identification cannot be separated from the interventions of the people who influence it, how women interpret and feel identity is closely related to social construction.

In short, the term masculinity should not have a relationship with humans who has a biologically male body, the attribute we call masculinity can be expressed with all kinds of bodies. More deeply we do not only know masculinity itself only on physical boundaries. Masculinity is not a gender restriction that is only appropriate for men to use. There is abundant evidence that masculinities are multiple, with internal complexities and even contradictions; also, masculinities change in history, and that women have a considerable role in making them, in interaction with boys and men. The American action cinema constructs gender roles, particularly the portrayal of the female characters as action heroines (Storey, 2001).

The data will be the answer to the problem question which was developed through structuralism analysis, which explains in detail on the data. The researcher looks for data relating to the question of the problem, how are the masculinity aspect of heroine described in Xena: Warrior Princess and The Hunger Games Movie. Then the researcher will interpret the data.

\section{LITERATURE REVIEW}

\section{Heroine}

In popular fiction when discussing heroism, heroine characters and heroes are the same concepts. Heroine is the female protagonist character in adventure stories. According to Hourihan (1997, p. 9) in her book, a hero encounters a series of difficulties and is threatened by dangerous opponents. The hero overcomes these opponents because he is strong, brave, resourceful, rational, and determined to succeed, he may receive assistance from wise and benefit being who recognize him for what he is. A hero is identical to men because a hero is always shown by masculinity. Women are required to behave like men: they are clever with bows and arrows and swords, become part of war and fight, and never give in to weakness (p. 67).

The heroine characters in a story are always faced with various challenges but then they are able to get through all the dangers for the sake of danger or they are confronted with many enemies with their extraordinary ability to conquer all enemies. Sometimes the hero character is portrayed by the author as the real world, building a certain imagination. This is built so that readers or viewers feel their real life.

\section{Masculinity}

The discussion about gender stereotypes indirectly directed into two categories of gender; masculine and feminine. Masculine and feminine have 
important concerns about characteristics as part of gender. In other words, spontaneously makes people think about masculine means all things related to men.

Connell, in her groundbreaking books, Gender and Power (1987), defines masculinity not as a type or essence of personality but as a place in social relations (masculine position), embodied practices (embodying masculinity), and a set of idealized value characteristics, which is called hegemonic masculinity. The term Connell's hegemonic masculinity is defined as the characteristics and practices embodied by men, dominating and their superiority over women. Therefore by realizing emphasized femininity, women occupy the same position.

Gender theory focuses on masculinity and femininity as personality and behavior types manifested by individual men and women. This theory focuses on how gender is expected and manifestated, and is culturally built in a society. According to Connell (1995, p. 29), masculinity is not an idea in the head or personal identity. It is also extended in the world, merged in organized social relations. Thus, the definition of masculinity above is to make clear that in order to have a good understanding or to do an analysis of masculinity, it cannot be treated as something completely general.

In conclusion, masculinity is an identity that is believed by the people in society associated engaged with men with certain characteristics. Masculinity in men is a cultural construction. Thus, construction that is influenced by the environment has the possibility to be found in women.

\section{METHOD}

In this research, it is necessary to use a method in conducting research. The researcher use comparative method to find out the location of the equations of the two objects studied so that the researchers used them as objects of research with the topic "woman characters". Comparative literature is the comparison of one literature with another or other, and the comparison of literature with other spheres of human expression (Bassnett, 1993, p. 31). According to Damono (2005), describe that comparative literature is the literary criticism beyond the boundaries of a country and study the relationship between science and literature with other beliefs such as, art, philosophy, history, and science social.

This method is devoted to describing or elaborating a problem selected on the two research objects. This method is a reference for researchers to explain further and thoroughly the topic of the research which is related to the characteristics of masculinity which the women have as the main characters.

\section{FINDINGS AND DISCUSSIONS}

The data resource of this research taken from Xena: Warrior Princess Television Series (1995) and The Hunger Games Movie (2012). The data resource of this research is taken from the film of "Xena: Warrior Princess Television Series (1995) and The Hunger Games Movie (2012) " and related to represent heroism act in their personality. According to Visser (2002) that the masculinity divided into several categories prototype. Visser also added the masculinity aspect divided some basic categories included: 
Table 1. Masculitiy Aspects

\begin{tabular}{|c|c|}
\hline \multicolumn{2}{|c|}{ Masculinity Aspects } \\
\hline Carrier-oriented & in control \\
\hline Independent & Self-reliant \\
\hline Strong & Commanding Respect \\
\hline $\begin{array}{c}\text { Finding pleasure in } \\
\text { control }\end{array}$ & Rational \\
\hline Active & Desiring Supremacy \\
\hline Adventurous & Sex is seen as power / \\
\hline Dominant & Empowering. \\
\hline Interested in technology & \\
\hline
\end{tabular}

Masculinity not only talks about men, but the term "masculinity" can also be found in women's bodies. In this understanding, social construction about the term masculinity is not only oriented towards men, basically, but masculinity is also a behavior carried in social life. So from this explanation, it can be said that masculine is only a character that can be developed by anyone and can choose what we want to be, so woman or man can be. Therefore, in this study, researchers will not discuss all the attributes but only choose some attributes of masculinity that match the characters in the film are dominant, independent, strong, rational thinking. Based on the statement above is the data that researchers found the attitude of masculinity represented of Katniss Everdeen and Xena. The data will be presented below:

Table 2. Types of Masculinity

\begin{tabular}{|c|c|c|c|c|}
\hline No & Dominant & Strong & $\begin{array}{c}\text { Self- } \\
\text { confident }\end{array}$ & Rational \\
\hline 1 & $\begin{array}{l}\text { The Hunger } \\
\text { Games, } \\
\text { Dominant } 1 \\
\text { minute- } \\
00: 19: 22\end{array}$ & $\begin{array}{l}\text { The Hunger } \\
\text { Games, } \\
\text { Strong } 1 \\
\text { minute - } \\
\text { 00:04:16 }\end{array}$ & $\begin{array}{l}\text { The Hunger } \\
\text { Games, Self- } \\
\text { Confident } 1 \\
\text { minute - } \\
00: 32: 55\end{array}$ & $\begin{array}{l}\text { The Hunge } \\
\text { Games, } \\
\text { Rational } 1 \\
\text { minute - } \\
\text { 01:34:57 }\end{array}$ \\
\hline 2 & $\begin{array}{l}\text { Xena: Warrior } \\
\text { Princess } \\
\text { Episode 1, } \\
\text { Dominant } 2 \\
\text { minute - } \\
00: 07: 21\end{array}$ & $\begin{array}{l}\text { Xena: } \\
\text { Warrior } \\
\text { Princess } \\
\text { Episode 1, } \\
\text { Strong } 2 \\
\text { minute - } \\
\text { 00:04:11 }\end{array}$ & $\begin{array}{l}\text { Xena: Warrior } \\
\text { Princess } \\
\text { Episode 10, } \\
\text { Self- } \\
\text { Confident } 2 \\
\text { minute - } \\
\text { 00:34:36 }\end{array}$ & $\begin{array}{l}\text { Xena: } \\
\text { Warrior } \\
\text { Princess } \\
\text { Episode 3, } \\
\text { Rational } 2 \\
\text { minute - } \\
\text { 00:33:08 }\end{array}$ \\
\hline
\end{tabular}




\section{Dominant}

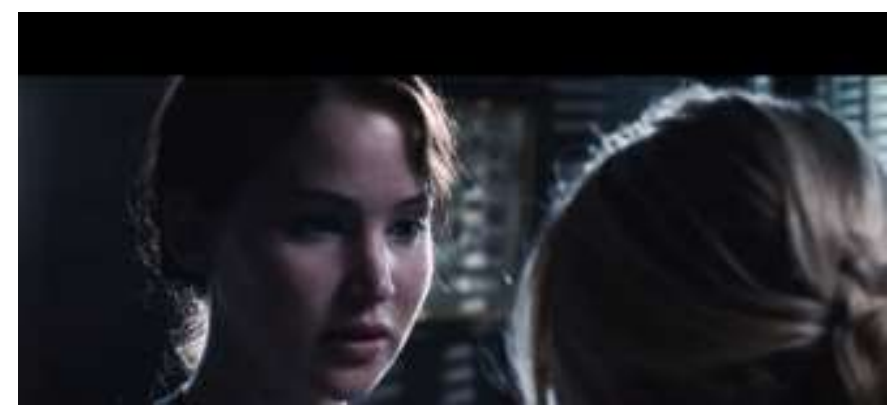

Dominant 1 (00:19:22)

Katniss : "Listen to me. You can't leave again."

Mother: "I know. I wont. I couldn't help what-"

Katniss: "Well, you have to help it this time. You can't clock out and leave Prim on her own. There's no me now to keep you both alive. It doesn't matter what happens, whatever you see on the screen. You have to promise me you'll fight through it! Mother pulls her arm away harshly. Don't cry! don't cry!"

The conversation above shows a conversation between Katniss and Mrs. Katniss is his mother which is indicated by the dominant conversation aspect of Katniss. The screenshot above shows the dominant attitude of Katniss for his family. Because he as head of the family and breadwinner for his family Katniss was worried to leave Prim, his sister, and his mother. Xena had to face The Hunger Games 74 'because he volunteered to replace his younger sister. Katniss said, "You can't clock out and leave Prim on her own", these are words of affirmation and dominant aspects. The attitude that Katniss displayed was a dominant aspect of masculinity in which he was responsible for his family. Just like a man in a family or in a house, he must always be reliable and responsible for anything. And Katniss shows that.

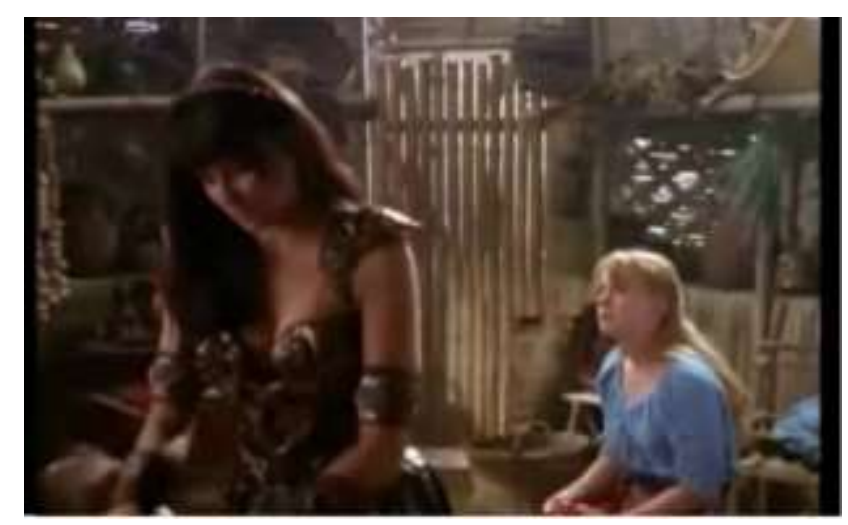

Dominant 2 Episode 1 (00:07:21)

The capture above shows Katniss's conversation with Gabrielle where Katniss showed the aspect of his dominance. The first dominant aspect of masculinity when she saved the village of Natch. As the capture above, Gabrielle was persuading Xena to ask her to go on an adventure together and also teach her many things. Gabrielle said, "I was born to do so much more." From this statement, 
Xena has displayed a profound influence on Gabrielle. From the discussion, Xena tried to show the element of her dominance in their discussions even when Gabrielle persuaded Xena to invite her, but Xena dominated when Gabrielle was not given the opportunity to negotiate it certainly made Gabrielle under her dominance was added when Xena made her decision, "Then you know already I'm not taking you with me. Don't think about that. Follow me". Her domination determines to Gabrielle's decision to give a contribution by giving her a weapon.

\section{Strong}

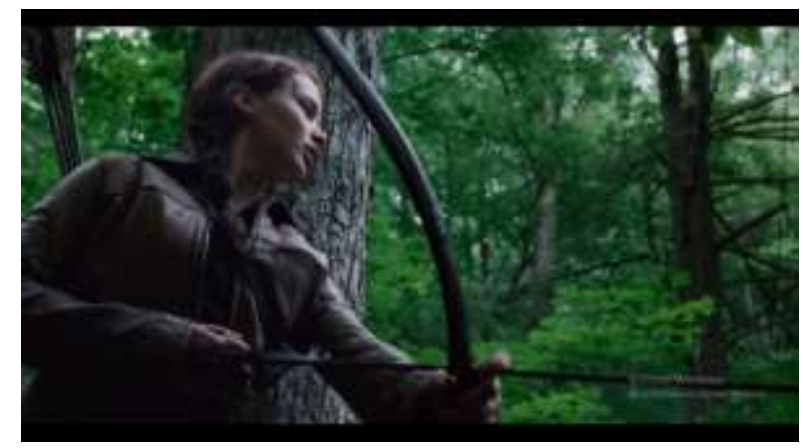

Strong 1 (00:04:16)

The first Katniss ability is the ability to shoot. Katniss learned archery from her father when she was little. Katniss's ability in archery is used for hunting which is nothing but to meet the needs of his family. Then in the selection of The Hunger Games Katniss also chose arrows and bows as his main weapon. Clever archery is one of the strengths he has to win battles. His strength in archery amazes anyone, for example when training sessions are held Katniss's ability to amaze the Gamemakers and get the highest score, then on the opportunity to shoot apples and destroy food supplies. But Katniss was unable to shoot and kill humans, when Katniss killed Cato Katniss felt guilty. This power is only obtained when we practice a lot.

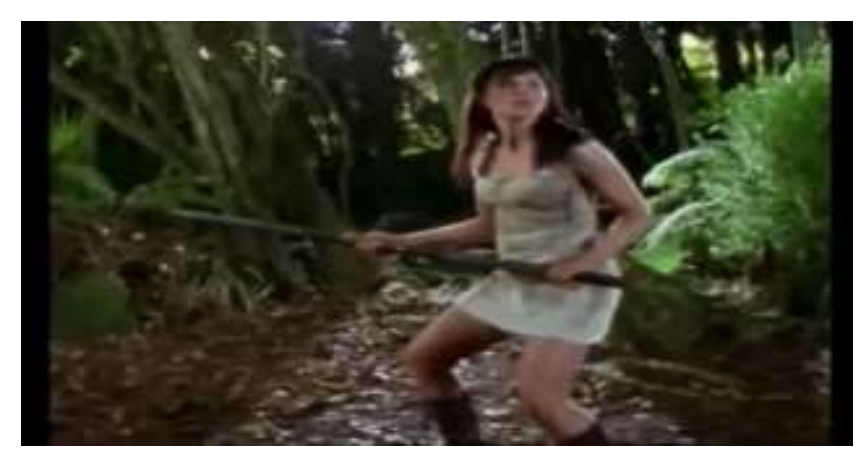

Strong 2 Episode 1 (00:04:11)

Xena is a warrior who has great strength. This character is required to have a superior character than anyone. In the screenshot above shows a picture of Xena has a strong character in her. It was proven from the fact that she was carrying weapons, Xena always carried weapons wherever she was. Xena's main weapons are Chakras and swords. A strong aspect of him was represented by his actions when she was facing different enemies or opponents. Its strength refers to the representation of physical strength and is ready to fight. She has a strong physique 
and high courage, because not every person can do such a thing and of course it must have strong physical abilities.

\section{Self-Confidence}

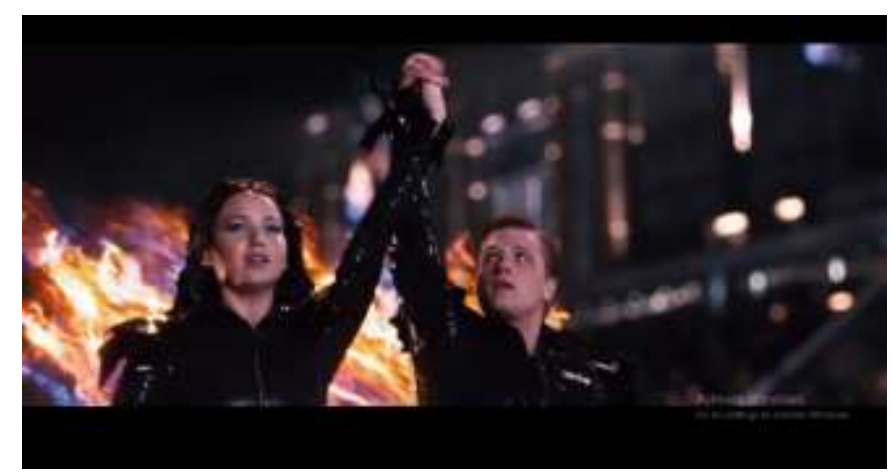

Self- Confident 1 (00:32:55)

Cinna: "Well see, and just take somebody that brave, shouldn't be dress to come some stupid costum that should they."

Cinna: "Don't be afraid!"

Katniss : "I'm not afraid!"

In the screenshot above, Katniss and Peeta are in a parade through the city street. She meets her Cinna stylist who comes up with an idea to impress people. Cinna dresses her up in a black shirt with fire that will not burn the shirt. However, Katniss always feels afraid of facing the Hunger Game and does not believe in his abilities, but with the strength of confidence given by Cinna, by saying "and just take somebody that brave, should not be dress to come some stupid costum that should they." Cinna knew that Katniss was a brave woman, so she had to convince Katniss that she could and try to awaken her self-confidence.

Then, her natural character of a woman is not eliminated even though she was made as masculinity in the story. In these words, Katniss says "I'm not afraid", this is Self Confident Katniss who began to wake up showing that self-confidence makes him not need to fear anything. This is also a side where she can help to grow self-confidence to get to know her character.

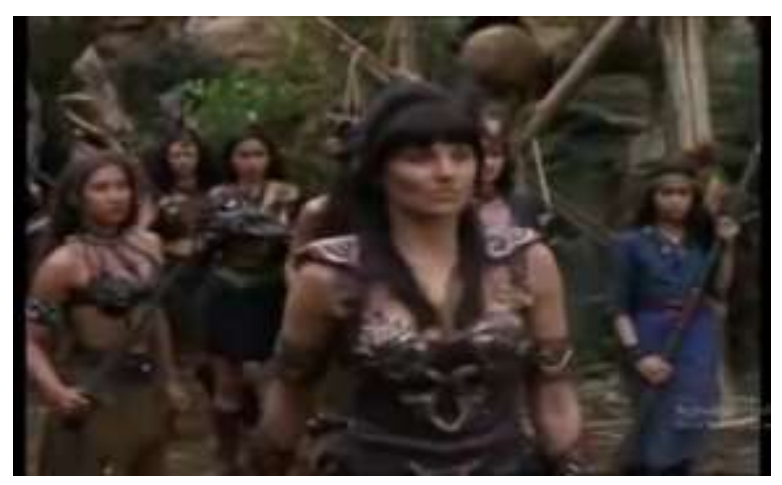

Self- Confident 2 Episode 10 (00:34:36)

Xena's confidence grows in a battle challenge between herself and Queen Melosa. Xena was involved in a decisive conversation. The conversation shows the self-confidence side that Xena had when she confidently chose the Royal Challenge and defeated Melosa. This action was carried out so that Melosa stopped the execution of Tildus. Xena said, "Queen Malosa I demand to challenge, the royal 
challenge must be on," that she has high confidence to win the challengge and she can increase the level of self-confidence and belief in her abilities.

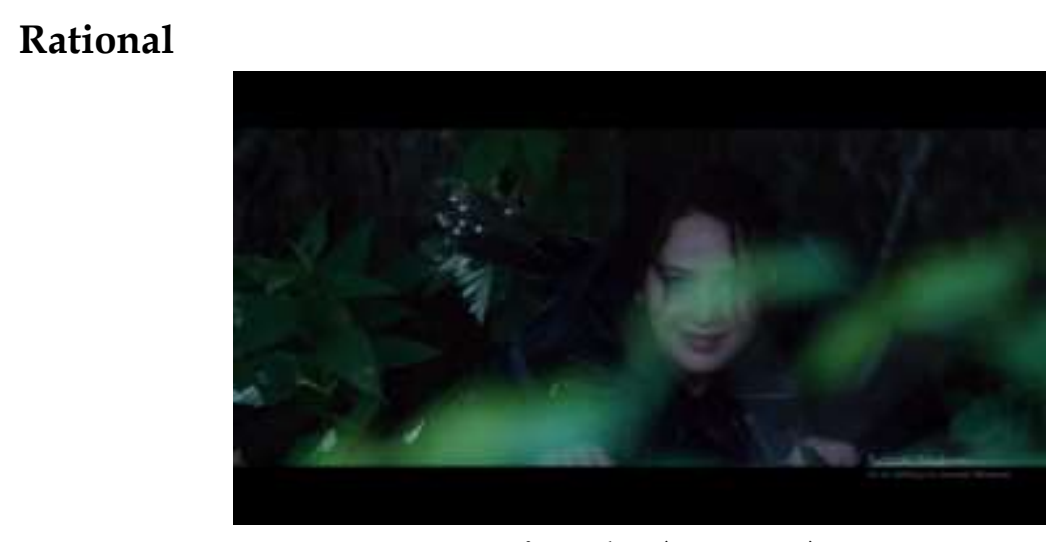

Rational 1 (01:34:57)

The capture above illustrates how Katniss used his tactics to make a plan. Katniss and Rue then plan to destroy the Careers' food and supply pile, with Katniss figuring that the Careers have had plenty of food for their whole lives and that they would struggle if a direct food supply was taken away from them, but finally, Katniss destroyed all food supplies where Karniss and Rue burned the leaves to make smoke so that there was nothing left. But to deceive Cato, he was making a fire to signify his existence. In another place, Katniss hides to shoot a sack that spills apples onto the ground, setting off all of the landmines. Nearly everything is destroyed and due to the explosion.

Following his thoughts and logical considerations, Katniss tried to save his life as well as Rue so that they did not have enough food storage. Her rational makes Katnissmore efficient to have a greater chance of winning. This gives room and high hopes for it. Better to use slow killing tactics than to kill directly. It represents that her rational gives her the advantage to solve the case because she does not hurry to make a decision. One of the characteristics of masculinity is a logical thought that is based on the beliefs of one's actions with the reason someone to act.

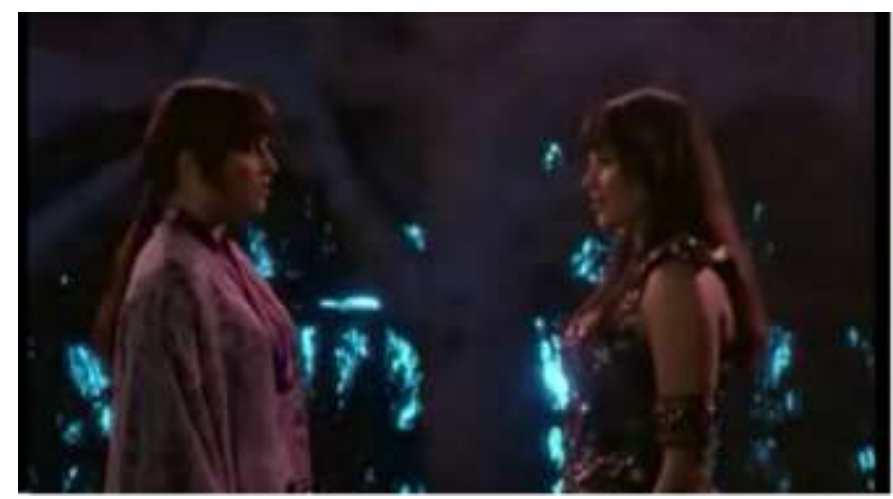

Rational 2 Episode 3 (00:33:08)

In the screenshot above shown that it makes Xena face to face with him directly. Xena was confronted with the thoughts she had to face and choose. In this scene, Xena is in Dreamscape. Where Xena entered the mystical world known as Dreamscape to save Gabrielle, who had been taken there and forced to complete a 
series of daunting tasks. Xena entered an altered state of consciousness and had to face ghosts from her past to save her friend.

On the way, she found his worst enemy was himself. But then, the two Xena defeated each other, but the original Xena still had the strength to keep on thinking logically, thus illustrating that the good Xena controls the old. It is represented by Xena wanted to run with it but she still thinks rational. So then Xena can control her emotions and thoughts to rational that all was wrong and she defeated herself in the past.

So, from the explanation above about the masculine aspect of Katniss and Xena, it can be concluded that the characters that show in the two main characters get significant relief and equality results. It is showed that the Katniss Everdeen character and Xena have several criteria each that make both of them unique. The characters of each film have their own characteristics. As explained earlier, one's interest in films is the image of a unique character who is able to bring the film to market success.

The characters possessed their own characters even though both have aspects of masculinity and has the similarities and differences between them. First, in the dominant masculinity aspect in the two objects, there are similarities that support both. Katniss and Xena have similarities in controlling the conversation in other words they are able to become dominant when confronted with anyone and also they are able to influence both the family and the environment. Second, in the second dominant aspect, namely strength, there are similarities and differences. The difference lies in how they fight and use weapons. Xena tends to master battle and weapons more than Katniss who only relies on his bow and arrow. The similarity lies how they are strong in dealing with every obstacle as well as the pain they receive.

Third, in the masculinity aspects of rational, there are similarities in both Katniss and Xena characters. They are both resourceful and clever in overcoming problems. The fourth is Self-Confidence. They have different characterizations. Xena tends to form more confidence than before because she was used to the battlefield. In another hand, Katniss needed more support from others to form his confidence.

\section{CONCLUSIONS}

The masculinity aspects constructed in Katniss and Xena character shows that the female action hero in those films has characters with masculinity aspects. Both of them have similarities and differences. Both have unique aspects and factors which become interesting elements in the film. Those films have the aspect of masculinity because the image of heroine in adventure story is someone who has special competence and makes the readers believe that the women character has masculinity aspect. This aspect will be necessary to face the obstacles and dangers, generally the role played by men. Then, both characters, Katniss and Xena as female masculinity act like men in some part of the film because the director wants to describe Katniss and Xena with the image of hero by using her aspects of masculinity. 


\section{REFERENCES}

Bassnett, S. (1993). Comparative Literature: A Critical Introduction. Cambridge: Blackwell Publishers.

Boggs, J. M., \& Petrie, D. W. (2008). The Art Of Watching Films : Seventh Edition. New York: McGraw-Hill.

Connell, R. (1987). Gender and Power: Society, the Person, and Sexual Politics. Stanford: CA: Stanford University Press.

Connell, R. W. (1995). Masculinities - 2nd ed. Berkeley and Los Angeles. California: Cniversity of California Press.

Damono, S. D. (2005). Pegangan Penelitian Sastra Bandingan. Jakarta: Pusat Bahasa.

Hourihan, M. (1997). Deconstrucing The Hero: Literary Theory and Children's Literature. London and New York: Routledge.

Radway, J. A. (1984). Reading the romance : women, patriarchy, and popular literature ; with a new introduction by the author. Chapel Hill and London: The University of North Carolina Press.

Saricks, G. J. (2009). The Readers' Advisory Guide to Genre Fiction. United States of America: American Library Association.

Storey, J. (2001). Cultural Theory And Popular Culture ; An Introduction 3rd edition. England: Pearson Education Limited.

Visser, I. (2002). Peototypes of Gender: Conceptions of Feminin and Masculine. Elsevier Science Ltd. 